\title{
Relationship between Heart Rate, Left Ventricular Output, and Stroke Volume in Preterm Infants during Fluctuations in Heart Rate
}

\author{
PER WINBERG AND ULF ERGANDER \\ Department of Pediatrics, Karolinska Institute, St. Göran's Children's Hospital and Karolinska Hospital, \\ Stockholm, Sweden
}

\begin{abstract}
The relationship between changes in heart rate, left ventricular output, and left ventricular stroke volume was studied in 18 preterm infants, with mean gestational age 29 wk (range 26-33 wk) and mean postnatal age $10 \mathrm{~d}$ (range 1-21 d). To yield left ventricular output, the blood flow velocity in the ascending aorta was measured by range-gated Doppler technique and multiplied by the aortic cross-sectional area measured by cross-sectional and M-mode echocardiography. Stroke volume was calculated by dividing left ventricular output by heart rate. The individual mean left ventricular output correlated poorly with heart rate $\left(r^{2}=0.17\right)$, and, accordingly, there was a closer relationship between stroke volume and left ventricular output. In only four of the 18 infants was a significant correlation between heart rate changes and left ventricular output found. Substantial changes in stroke volume were seen in most infants, and in 13 of the 18 infants the changes exceeded $25 \%$. These variations in stroke volume were closely related to left ventricular output. In 15 of the 18 infants, the maximum heart rate change was associated with a stroke volume change in the opposite direction. The group average of the maximum heart rate increase in each individual, $24 \mathrm{bpm}(18 \%)$, corresponded to a decrease in stroke volume of $0.15 \mathrm{~mL} \cdot \mathrm{kg}^{-1}(9 \%)(p<0.05)$ and an increase in left ventricular output of $22.7 \mathrm{~mL} \cdot \mathrm{min}^{-1} \cdot \mathrm{kg}^{-1}$ $(9 \%)(p<0.05)$. A reciprocal relationship was seen between afterload and left ventricular output. The findings indicate that the preterm infant has a substantial ability to alter stroke volume and that stroke volume is an important determinant of neonatal left ventricular output. During beat-to-beat fluctuations in heart rate, the stroke volume changes appear to reduce the effect of the heart rate changes on output. (Pediatr Res 31: 117-120, 1992)
\end{abstract}

\section{Abbreviations}

\section{HR, heart rate}

LVO, left ventricular output

SV, stroke volume

SVR, systemic vascular resistance

BP, blood pressure

PDA, patent ductus arteriosus
Studies of the fetal and neonatal heart have provided basic information about the myocardial immaturity on the cellular and subcellular levels. The immature myocardium has been shown to contain more water, less contractile elements per unit weight, and less sarcoplasmic reticulum $(1,2)$. Furthermore, the cardiac sympathetic innervation is not fully developed at birth $(3,4)$. In in vitro experiments these differences correspond to reduced compliance and reduced contractile force (1) compared with the mature myocardium. However, the hemodynamic consequences of the myocardial immaturity on the intact circulatory system are, despite extensive investigations, still not clearly delineated. It has been claimed that the fetal heart performs at or near its peak capacity even during normal conditions and has a very limited ability to change (SV) $(5,6)$. Accordingly, fetal and neonatal cardiac output should be almost entirely dependent on HR. This, however, has been questioned in other fetal and neonatal lamb studies (7-10), as well as in human fetal and neonatal studies (11-14). In an earlier study using the ultrasound Doppler technique, we found that changes in LVO during the postnatal circulatory transition in healthy term infants seemed to be mainly effected by changes in SV and not HR (14). The same relationship between $\mathrm{LVO}, \mathrm{SV}$, and $\mathrm{HR}$ has recently been reported for the preterm infant undergoing ligation of the ductus arteriosus (13). The aim of this study was to investigate this relationship during short time fluctuations in HR.

\section{MATERIALS AND METHODS}

Eighteen preterm infants with gestational age less than $34 \mathrm{wk}$ were studied. Infants with asphyxia, malformations, or septicemia were not included. The infants were nursed in closed incubators, and their fluid intake was $120 \mathrm{~mL} / \mathrm{kg} / 24 \mathrm{~h}$. At the time of the study, all infants had normal blood gases and no drugs, except minerals and vitamins, were used.

LVO was measured using the ultrasound Doppler technique first described in infants by Alverson et al. (15). The blood flow velocity in the ascending aorta was measured using a range-gated Doppler velocimeter (ALFRED, Vingmed A/S, Oslo, Norway). A 5-MHz transducer, with an 8-mm diameter tip, was positioned in the suprasternal notch and directed toward the ascending aorta. The echoes from the aortic valve were identified, and the sample volume, with a length of about $4 \mathrm{~mm}$, was located 5-10 $\mathrm{mm}$ above the valves. By making small changes in the probe angle, the investigator searched for the highest velocity. A $400-$ $\mathrm{Hz}$ high-pass filter was used to reduce noise from vessel wall motions. The space average velocity (the average velocity over the cross-section of the aorta) and the mean flow velocity (the temporal mean of the space average velocity) signals were recorded on an oscillograph (Mingograph, Siemens Elema, Stockholm, Sweden). The Doppler recordings were continued for 20 30 min in each infant to allow for HR changes. The portions of the tracings with low quality, mostly caused by noise and artifacts 
from infant movement, were rejected. The portions of high quality were selected for analysis, and, in these parts, the mean flow velocity was calculated using the internal calibration signal of the instrument. The simultaneous HR was calculated over five heart beats from the space average velocity curve.

Cross-sectional and M-mode echocardiography was used to determine the end-systolic internal diameter of the ascending aorta $5 \mathrm{~mm}$ above the aortic valve. The calculated aortic crosssectional area was multiplied by the mean flow velocity and divided by body weight to give LVO in $\mathrm{mL} \cdot \mathrm{min}^{-1} \cdot \mathrm{kg}^{-1}$. SV was calculated by dividing LVO by HR. Arterial BP was measured in the right upper arm using the oscillometric technique (Omega 1400 , In vivo Research Lab, Inc., Broken Arrow, OK). The mean value of three BP measurements was used. SVR was calculated by dividing mean BP by LVO.

Of all determinations of LVO, SV, and HR in each infant, a selection was made to obtain one LVO and SV value for every HR. When there were several LVO determinations for a given $\mathrm{HR}$, the highest LVO was chosen. Thus, five to $14 \mathrm{HR}$, LVO, and SV determinations in each infant were obtained. The number of determinations in each infant depended on how much the HR fluctuated.

Color Doppler echocardiography was also used to assess ductal shunting. Based on disturbances of flow in the pulmonary artery, left atrial size, and presence of reversed diastolic flow in the descending aorta, the infants were classified as having 1) no or minimal ductal shunt (no ductal flow detected or color flow mapping showing only minimal flow disturbance in the pulmonary artery close to the ductus); 2) moderate shunt (flow disturbance in a larger part of the pulmonary artery; left atrium to aortic ratio $<1.25$ and no diastolic reversal of flow in the descending aorta); or 3) large shunt (left atrium to aortic ratio $>1.25$; diastolic reversal of flow in the descending aorta).

The study was approved by the local committee of ethics, and informed consent from the parents was obtained before the investigation.

The statistical evaluation was made by the Mann-Whitney two-sample test, $t$ test, and linear regression. Linear regression, however, was only used to analyze the relationship between HR and LVO, because these were the only variables that were measured independently of each other. SV was directly derived from LVO, and regression may accordingly not be used to analyze the LVO-SV relationship.

\section{RESULTS}

The clinical data for the study group are shown in Table 1. The group mean LVO was $257 \mathrm{~mL} \cdot \mathrm{min}^{-1} \cdot \mathrm{kg}^{-1}$ (range $125-496$ $\left.\mathrm{mL} \cdot \mathrm{min}^{-1} \cdot \mathrm{kg}^{-1}\right)$. No infant had echocardiographic signs of a large ductus shunt, and none was considered for surgical or pharmacologic closure of the ductus. Four infants had a moderate ductus shunt and showed a higher LVO $\left(388 \mathrm{~mL} \cdot \mathrm{min}^{-1}\right.$. $\left.\mathrm{kg}^{-1}\right)$ than those without ductus shunt $\left(216 \mathrm{~mL} \cdot \mathrm{min}^{-1} \cdot \mathrm{kg}^{-1}\right)$ $(p<0.01)$. This was mostly related to higher SV in infants with

Table 1. Clinical data in 18 preterm infants*

\begin{tabular}{lcrr}
\hline & Mean & \multicolumn{1}{c}{ Range } & $n$ \\
\hline Gestational age (wk) & 29.6 & $(26-33)$ & \\
Birth weight (g) & 1363 & $(696-2200)$ & \\
Age at study (d) & 10.3 & $(1-21)$ & \\
Weight at study (g) & 1317 & $(675-2154)$ & \\
BPm (mm Hg) & 46 & $(36-61)$ & \\
5-min Apgar score & 8.6 & $(7-10)$ & \\
Hematocrit & 55 & $(41-64)$ & \\
Moderate PDA & & & 4 \\
Ventilator & & & 3 \\
CPAP & & & 4 \\
\hline
\end{tabular}

* BPm, mean arterial pressure; CPAP, continuous positive airway pressure. a moderate ductus shunt than in those without ductus shunt (2.51 and $1.57 \mathrm{~mL} \cdot \mathrm{kg}^{-1}$, respectively) $(p<0.01)$, but was also related to higher HR (156 and $139 \mathrm{bpm}$, respectively) $(p<0.05)$.

A poor correlation was found between mean HR and mean LVO for each infant $\left(r^{2}=0.17\right)$ (Fig. 1). Accordingly, a stronger association was found between mean SV and mean LVO (Fig. 2).

The range of fluctuation in HR varied markedly among the infants. In 14 of 18 infants, the HR changes were larger than $14 \%$. A significant HR-LVO correlation was seen in only four of 18 infants. Substantial SV changes were seen in most infants, and in 13 of 18 these changes exceeded $25 \%$. These variations in SV were closely related to LVO changes (Fig. 3). Although a direct relationship between changes in HR and changes in LVO was found, this was obvious for single observations only with larger HR changes (Fig. 4). Small LVO changes however, might not be discerned by the method, and to overcome this problem the recordings in each infant with the maximum and the minimum HR were selected and the group data were analyzed. The individual maximum HR change ranged from $9 \mathrm{bpm}(7 \%)$ to 84 bpm $(127 \%)$. The maximum HR change was inversely related to the SV change in 15 of 18 infants and directly related to the

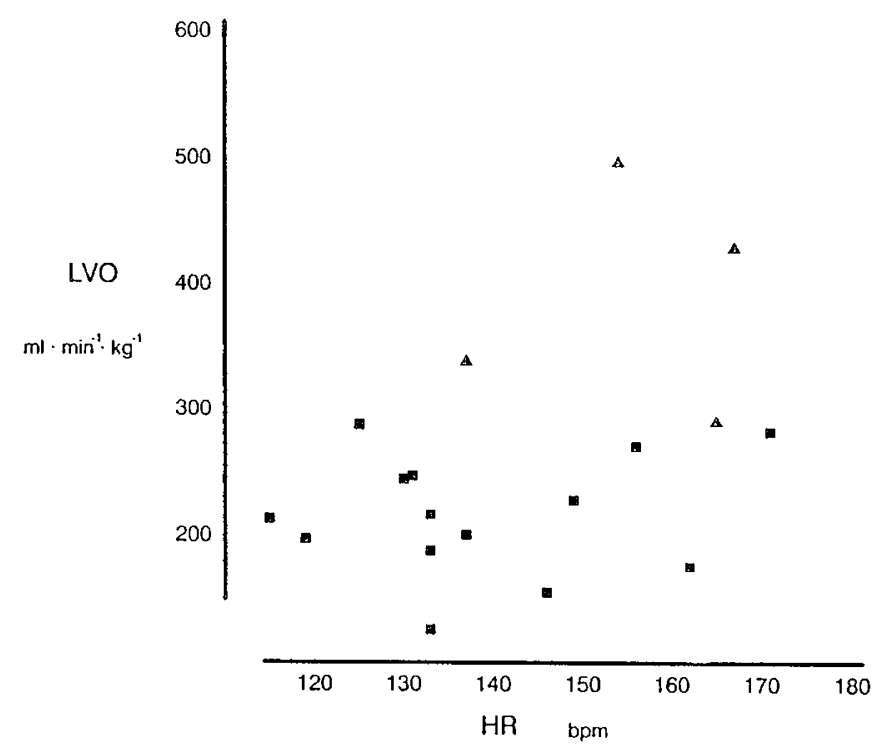

Fig. 1. Mean HR and mean LVO in 18 preterm infants with $(\mathbf{\Lambda})$ and without (回 PDA.

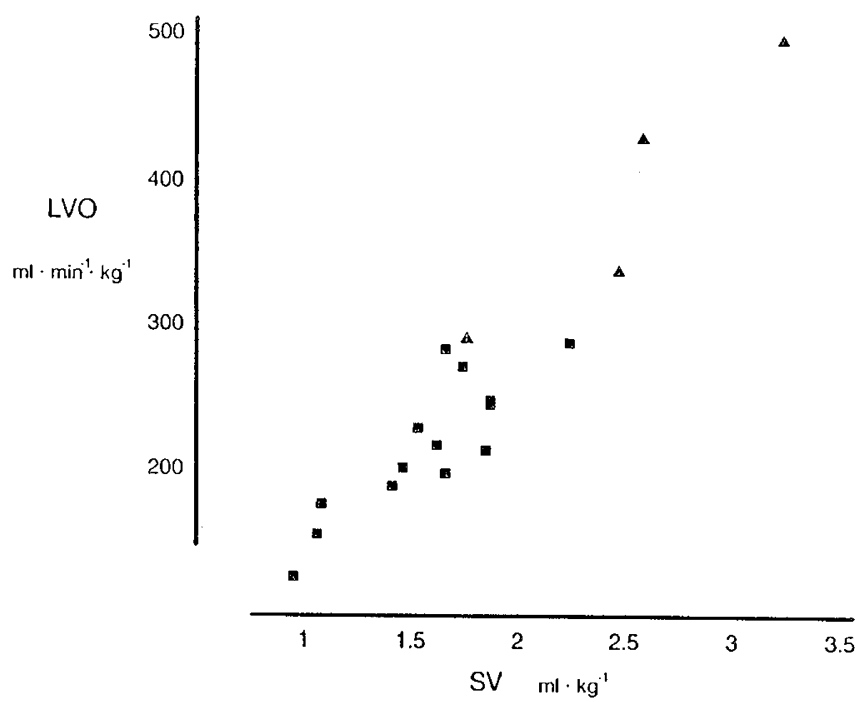

Fig. 2. Mean $\mathrm{SV}$ and mean $\mathrm{LVO}$ in 18 preterm infants with $(\boldsymbol{\Lambda})$ and without (西) PDA. 


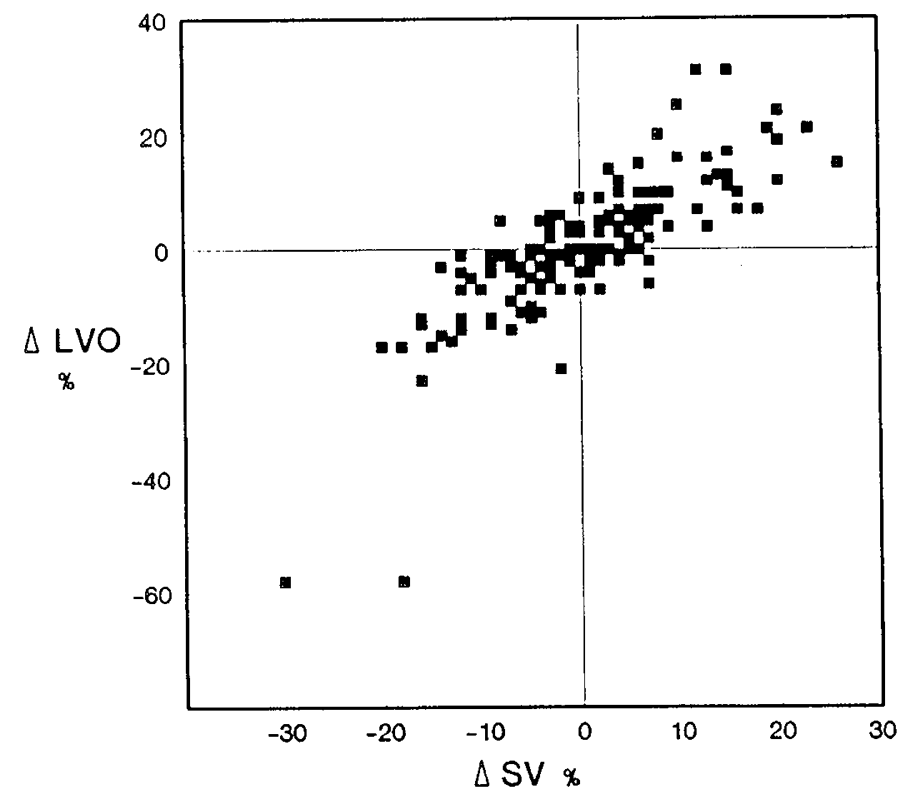

Fig. 3. Plot of the relative changes from the mean in SV and LVO in 18 preterm infants.

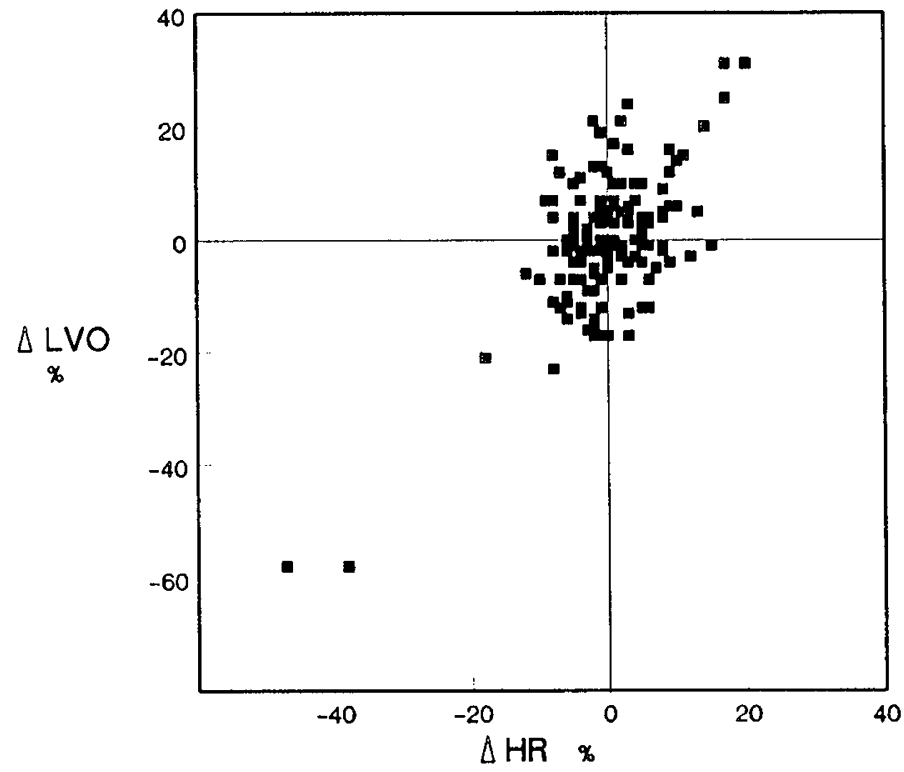

Fig. 4. Plot of the relative changes from the mean in HR and LVO in 18 preterm infants.

LVO change in 12 of 18 infants. The group average of the maximum $\mathrm{HR}$ increase, $24 \mathrm{bpm}(18 \%)$, corresponded to an increase in LVO of $22.7 \mathrm{~mL} \cdot \mathrm{min}^{-1} \cdot \mathrm{kg}^{-1}(9 \%)(p<0.05)$ and a decrease in $\mathrm{SV}$ of $0.15 \mathrm{~mL} \cdot \mathrm{kg}^{-1}(9 \%)(p<0.05)$. A reciprocal SVR-LVO relationship was found (Fig. 5). SVR was lower in infants with PDA $(p<0.01)$. Mean BP was $41.0 \mathrm{~mm} \mathrm{Hg}$ in infants with PDA and $47.5 \mathrm{~mm} \mathrm{Hg}$ in infants without PDA (NS).

\section{DISCUSSION}

The ultrasound Doppler technique for measurement of LVO is especially useful in neonates because it is strictly noninvasive and inflicts a minimum of stress on the infants. It also allows measurements of beat-to-beat changes. The method has been validated in several studies in newborn infants, and a good correlation with other techniques has been demonstrated (1517). A good reproducibility has also been shown for the method (17-19). Slightly different methods for the velocity and the

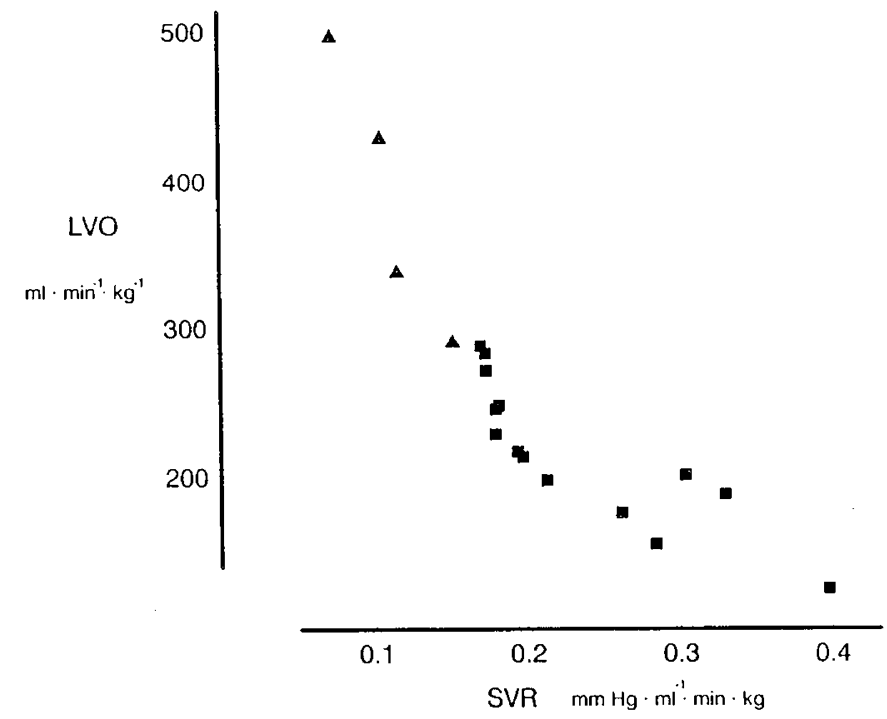

Fig. 5. Mean SVR and LVO in 18 preterm infants with $(\mathbf{\Lambda})$ and without (ם) PDA.

diameter measurements have been used. The product of the cross-sectional mean flow aortic velocity and the cross-sectional area derived from the inner aortic diameter should yield the most accurate measure of output (17). In the present study, a variation coefficient of $8 \%$ was estimated using the multiple aortic blood flow velocity determinations at the same $H R$ in each infant. In the ultrasound Doppler technique, as in most other techniques for LVO measurements, SV is calculated directly from LVO. Thus, an over- or underestimation of LVO directly affects SV in the same direction, and the relationship between LVO and SV might accordingly be overemphasized. The close association between SV and LVO changes shown in Figure 3 must accordingly be interpreted with caution. A considerable number of the observations, however, show changes too large to be explained by methodologic errors only, and SV does seem to be of importance to LVO changes.

The group mean LVO, in both the infants with PDA (388 $\left.\mathrm{mL} \cdot \mathrm{min}^{-1} \cdot \mathrm{kg}^{-1}\right)$ and those without PDA $\left(216 \mathrm{~mL} \cdot \mathrm{min}^{-1} \cdot \mathrm{kg}^{-1}\right)$, are in good agreement with previous reports in preterm infants $(13,20,21)$.

Reactions from the manipulation of the transducer in the suprasternal notch probably accounted for most of the HR changes. However, HR changes that were not clearly related to the interference of the transducer were also seen.

The absence of a detectable effect on LVO by smaller HR changes might suggest that SV changes compensated for the HR change and that LVO does not change until this compensatory ability is exceeded. However, the methodologic error in the LVO determination might obscure effects of smaller HR changes. To overcome this, the effect of the maximum HR change was investigated and the grouped data was analyzed. Statistically significant relationships were found. The SV changes related inversely to the HR changes, thus diminishing the effect of $H R$ on LVO. Thus, under otherwise stable conditions, it appears that the beat-to-beat fluctuations in HR are counterbalanced by changes in SV. The finding that both SV and HR are higher in the infants with PDA suggests that when volume demand is increased, there are parallel changes in HR and SV to accomplish an elevated LVO.

In a few cases, HR and SV changed in the same direction, e.g. in the infant with the most marked bradycardia the decrease in HR to 66 bpm (56\%) was accompanied by a $27 \%$ decrease in $\mathrm{SV}$, leading to a $68 \%$ decrease in LVO. Possibly the same stimulus that caused the more substantial change in HR also affected other factors that may directly influence SV, such as afterload, diastolic filling, or myocardial contractility. For ex- 
ample, a vagal response includes bradycardia, increased vascular resistance, and decreased contractility (22) and is a possible explanation for the considerable decrease in both HR and SV.

Conflicting results have been obtained regarding the relationship between HR, SV, and output in the immature heart. Rudolph and Heymann (6) found a direct relationship between HR and LVO, with very small changes in SV, whereas Kirkpatrick et al. (7) showed that LVO was constant over a wide range of $\mathrm{HR}$, indicating a substantial ability of the immature heart to change SV. Both studies were performed in chronically instrumented fetal lambs. In a later study, Anderson et al. (8) reevaluated this issue and found no simple relationship between HR, $\mathrm{SV}$, and LVO. Instead, HR interacted in a complex fashion with ventricular filling and contractility to modulate output. Atrial pacing showed no effect or negative effect on output. Spontaneous HR changes were mostly directly related to LVO and inversely related to SV, although in several cases HR and SV changes in the same direction. Thus, their results seem to be in agreement with those in the present study.

The vascular resistance calculated from mean BP and LVO will not only measure the resistance in the systemic circulation, but also reflect the resistance in the ductus and the pulmonary vascular bed if the ductus remains open. It is, accordingly, a measure of the total afterload resistance seen by the left ventricle, which probably explains the low SVR values in the infants with PDA. These infants are also likely to have an increased diastolic filling, which in combination with the low SVR contributes to an enhanced left ventricular performance and a further increased SV and LVO.

The reciprocal SVR-LVO relationship (Fig. 5), agrees well with most earlier studies, where fetal and neonatal LVO have been found to be sensitive to afterload changes $(23,24)$. In contrast, Baylen et al. (25) found no changes in LVO and SV in response to an acutely increased afterload in preterm sheep. Their study, however, was performed in the first hours after birth during the maximal catecholamine surge, which might have increased the contractile reserve.

This study does not support the view that SV is constant in the neonatal period and that LVO is almost totally dependent on HR. In contrast, the study indicates that the preterm infant has a substantial ability to alter SV. These SV changes are mostly inversely related to the beat-to-beat fluctuation in $\mathrm{HR}$ and appear to modulate the effect of HR on LVO. Thus, SV seems to be an important determinant of neonatal LVO.

\section{REFERENCES}

1. Friedman WF 1972 The intrinsic physiologic properties of the developing heart. Prog Cardiovasc Dis 15:87-111

2. Fisher J, Towbin J 1988 Maturation of the heart. Clin Perinatol 15:421-445

3. Friedman WF, Pool PE, Jacobowitz D, Seagran SC, Braunwald E 1968 Sympathetic innervation of the developing rabbit heart: biochemical and histochemical comparisons of fetal, neonatal, and adult myocardium. Circ Res 23:25-32

4. Lebowitz EA, Novick JS, Rudolph AM 1972 Development of myocardial sympathetic innervation in the fetal lamb. Pediatr Res 6:887-893

5. Rudolph AM 1974 Changes in the circulation after birth. In: Congenital Heart Diseases. Year Book Medical Publishers, Chicago, pp 17-28

6. Rudolph AM, Heymann MA 1976 Cardiac output in the fetal lamb: the effects of spontaneous and induced changes of heart rate on right and left ventricular output. Am J Obstet Gynecol 124:183-192

7. Kirkpatrick SE, Pitlick PT, Naliboff J, Friedman WF 1976 Frank-Starling relationship as an important determinant of fetal cardiac output. Am J Physiol 231:495-500

8. Anderson PAW, Glick KL, Killam AP, Mainwaring RD 1986 The effect of heart rate on in utero left ventricular output in the fetal sheep. J Physiol (Lond) 372:557-573

9. Baylen BG, Ogata $\mathrm{H}$, Oguchi K, Ikegami M, Jacobs H, Jobe A, Emmanouilides GC 1985 Left ventricular performance and contractility before and after volume infusion: a comparative study of preterm and full-term newborn lambs. Circulation 73:1042-1049

10. Clyman RI, Mauray F, Heyman MA, Roman C 1987 Cardiovascular effects of patent ductus arteriosus in preterm lambs with respiratory distress. J Pediatr 111:579-587

11. Lingman G, Marsal K 1986 Circulatory effects of fetal cardiac arrhythmias. Pediatr Cardiol 7:67-74

12. Tonge HM, Wladimiroff JW, Noordam MJ, Stewart PA 1986 Fetal cardiac arrhythmias and their effect on volume blood flow in descending aorta of human fetus. J Clin Ultrasound 14:607-612

13. Lindner W, Seidel M, Versmold HT, Döhlemann C, Riegel KP 1990 Stroke volume and left ventricular output in preterm infants with patent ductus arteriosus. Pediatr Res 27:278-281

14. Winberg P, Lundell BPW 1990 Left ventricular stroke volume and output in healthy term infants. Am J Perinatol 7:223-226

15. Alverson DC, Eldridge MW, Dillon T, Yabek SM, Berman W 1982 Noninvasive pulsed Doppler determination of cardiac output in neonates and children. J Pediatr 101:46-50

16. Goldberg S, Sahn DJ, Allen HD, Valdes-Cruz L, Hoenecke H, Carnahan Y 1982 Evaluation of pulmonary and systemic blood flow by 2-dimensional Doppler echocardiography using fast Fourier transform spectral analysis. Am J Cardiol 50:1394-1400

17. Mellander M, Sabel K-G, Caidahl K, Solymar L, Eriksson B 1987 Doppler determination of cardiac output in infants and children: comparison with simultaneous thermodilution. Pediatr Cardiol 8:241-246

18. Claflin KS, Alverson DC, Pathak D, Angelus P, Backstrom C, Werner S 1988 Cardiac output determinations in the newborn. Reproducibility of the pulsed Doppler velocity measurement. J Ultrasound Med 7:311-315

19. Hudson I, Houston A, Aitchinson T, Holland B, Turner T 1990 Reproducibility of measurements of cardiac output in newborn infants by Doppler ultrasound. Arch Dis Child 65:15-19

20. Alverson DC, Eldridge MW, Johnson JD, Burstein R, Papile L-A, Dillon T, Yabek S, Berman W 1983 Effect of patent ductus arteriosus on left ventricular output in premature infants. Pediatrics 102:754-757

21. Mellander M, Larsson LE 1988 Effects of early left-to-right ductus shunting on left ventricular output and cerebral blood velocity in preterm infants with and without severe lung disease. J Pediatr 113:101-109

22. DeGeest H, Levy MN, Zieske H, Lipman RI 1965 Depression of ventricular contractility by stimulation of the vagus nerves. Circ Res 18:222-235

23. Teitel D, Rudolph AM 1985 Perinatal oxygen delivery and cardiac function. Adv Pediatr 32:321-347

24. Gilbert RD 1982 Effects of afterload and baroreceptors on cardiac function in fetal sheep. J Dev Physiol 4:299-309

25. Baylen BG, Youtaro A, Padbury JF, Ikegamo M, Jobe AH, Emmanouilides GC 1989 Hemodynamic and neuroendocrine adaptations of the preterm lamb left ventricle to acutely increased afterload. Pediatr Res 26:336-342 